\title{
Clinical Presentations of Cytomegalovirus Infection in Immunocompetent Hosts
}

\author{
Suma Rao ${ }^{1}$, Shrikant D Pande ${ }^{1 *}$, Rahat Hussain ${ }^{2}$, Daphne Ang ${ }^{1}$ and Jonathan Seah ${ }^{1}$ \\ ${ }^{1}$ Changi General Hospital, Singapore \\ ${ }^{2}$ Ophthalm, Singapore National Eye Centre, Changi General Hospital, Singapore
}

"Corresponding author: Shrikant D Pande, Department of Rehabilition medicine, Changi General Hospital, 2 Simei St 3, Singapore, 529889, Tel: 65 96795556; E-mail: shrikantpande@yahoo.co.uk

Received date: July 24, 2018; Accepted date: September 30, 2018; Published date: October 05, 2018

Copyright: @ 2018 Rao S, et al. This is an open-access article distributed under the terms of the Creative Commons Attribution License; which permits unrestricted use; distribution; and reproduction in any medium; provided the original author and source are credited.

\begin{abstract}
Background and Aims: Cytomegalovirus (CMV) infection is well known in immunocompromised hosts. However, its incidence and role in immunocompetent subjects is not clear. The aim of our study was to evaluate CMV infection in immunocompetent hosts and its clinical presentations at a Government restructured hospital in Singapore.

Methods: We retrospectively reviewed in-patient referrals during the period June 2011 - June 2017 to one Infectious Diseases (ID) physician. Of all the referrals, only those with confirmed diagnosis of CMV in patients above the age of 21 years were analysed. All the patients were investigated for underlying immunodeficiency syndromes, inflammatory bowel diseases and malignancies. The diagnosis of CMV was confirmed using CMV quantitative PCR (Polymerase Chain Reaction), IgM, IgG, CMV antigen or histopathological examination of biopsy specimen: presence of CMV inclusion bodies. Acute infection was defined as positive IgM anti-CMV antibodies along with clinical features of CMV infection.
\end{abstract}

Results: Nine patients had confirmed CMV infection with age range of 32 to 79 years. Four patients presented with pyrexia of unknown origin (PUO), three with gastrointestinal manifestations and two had eye manifestations. Patients with PUO were younger with milder symptoms, and mild transaminitis. Those with gastrointestinal CMV were older and with severe symptoms needing prolonged hospitalisation and those with eye manifestations of CMV had localised symptoms.

Conclusion: CMV infection can present in immunocompetent and young subjects with local or systemic manifestations. Younger patients with CMV seem to have relatively mild illness even without antiviral treatment. CMV infections should be considered in young or older immunocompetent people even in the absence of any significant comorbidities and risk factors. As gastrointestinal manifestations seem to be more in elderly and associated with increased morbidity and mortality, early diagnosis and treatment of CMV in this group of people is important.

Keywords: CMV; Immunocompetent; Immunocompromised Inflammatory bowel disease

\section{Introduction}

Cytomegalovirus (CMV) is a double-stranded DNA virus member of Herpesviridae family. A majority of the human population is exposed to CMV, based on sero-prevalence. CMV establishes latent infection and may re-activate later and cause significant clinical manifestations, especially in immunocompromised patients, like those on immunosuppressant drugs and cancer chemotherapy, post-organ transplantation and acquired immunodeficiency syndrome (AIDS) [1].

The clinical manifestations of CMV infection in immunocompetent people, however, are less widely known and hence less understood. Usually the manifestations in immunocompetent people are due to primary infection or reactivation of underlying CMV infection, the differentiation between which is difficult in clinical practice. The manifestations may vary from mild and self-limiting to severe and debilitating.
In immunocompetent people, the infection is less well-studied and is thought to be mild and self-limiting illness; the role of antiviral treatment in these patients and the dose and duration are not wellestablished [1].

The aim of our study was to evaluate CMV infection and its clinical presentations among immunocompetent hosts.

\section{Material and Methods}

\section{Setting}

Changi General Hospital (CGH), Singapore, is a Government restructured hospital with all specialist care facilities except for women and child health. Its Infectious Diseases Department receives referrals from all other departments for diagnostics and therapeutics. SingHealth (CGH is a member of SingHealth group of hospitals in Singapore) centralised IRB approved this study for data collection. Due to retrospective nature of the study, waiver of consent was granted. 
Referrals to one Infectious Disease (ID) physician were reviewed from June 2011 to June 2017 for patients aged above 21 years.

All the in-patient data, demographic details, admission records in electronic and paper format, investigations and follow-up records were reviewed and documented. This material was collected and kept anonymised in electronic format and was housed on the hospital computer.

\section{Exclusion criteria}

Age below 21 years; patients with known HIV (Human Immunodeficiency Virus) or AIDS (Acquired Immuno-deficiency Syndrome); hepatitis, cirrhosis; those with end-stage renal disease and on haemodialysis; those on steroids or immunosuppressant treatment; post-organ transplant; immunodeficiency syndromes; patients receiving chemotherapy; patients with end-organ complications of diabetes; inflammatory bowel disease(IBD) and tuberculosis.

\section{Pyrexia of unknown origin (PUO)}

The criteria for consideration of fever as PUO were fever for atleast2-3 weeks and other causes of fever ruled out with intense inpatient evaluation.

\section{Diagnostic criteria used for confirmation of CMV}

CMV quantitative PCR (polymerase chain reaction), and/or CMV antigen, CMV IgM and IgG levels using peripheral blood samples.

Histopathological Examination: Presence of CMV inclusion bodies on biopsy using immunohistochemistry stain.

Acute infection was defined as positive IgM anti-CMV antibodies along with clinical features of CMV infection.

Diagnosis was confirmed on the basis of CMV quantitative PCR.

For blood PCR, kits and methods used: Real-time quantitative PCR(Roche COBAS Ampli Prep/COBAS, Taq Man, Roche Diagnostics, Indianapolis, IN 46250-0457, USA.

CMV Test with primers and probe targeted at UL54 gene of human Cytomegalovirus (CMV). Assay type: quantitative. Performance characteristics - Analytical sensitivity: EDTA plasma, $56 \mathrm{IU} / \mathrm{ml}$ at $95 \%$ confidence level. Analytical specificity: No cross-reactivity with HHV6, HSV1/2, VZV, EBV, Parvovirus, B19, Hepatitis B virus and BK virus. Dynamic (linear) range: 13, 7(2.14 log) to $9,100.000(6.96 \mathrm{log}) \mathrm{IU} / \mathrm{ml}$, $150(2.18 \mathrm{log})$ to $10,000,000(7.00 \mathrm{log})$ copies $/ \mathrm{ml}$, (Log values: $1 \log 10$ is: 10 copies $/ \mathrm{ml})$.

\section{Result}

\section{Case series of cytomegalovirus infection in immunocompetent patients}

Four patients reported with pyrexia of unknown origin, three patients with gastrointestinal and two with ocular manifestations of CMV infection.

\section{Patients presenting with pyrexia of unknown origin (PUO)}

Self-limited infections; No treatment was given in the form of antibiotics or antivirals.
1. A 37-year-old male with a history of ureteric calculus, presented with fever for 3 weeks, diarrhoea and generalised body aches. General and systemic examination was normal. Investigations revealed peripheral blood film: atypical lymphocytes (34\%), CMV PCR in peripheral blood: 2.76 log., mild transaminitis.

2. A 32-year-old male, with nephrolithiasis and prolapsed intervertebral disc was admitted with a 2-week history of fever. General physical and systemic examination revealed no abnormality. Peripheral blood film showed atypical lymphocytes (13\%); CMV IgM: Positive; IgG: positive; CMV PCR: 2.21 log; mild transaminitis.

3. A 31-year-old male, with a history of gastrointestinal reflux disease, was admitted with fever of 3-week duration and dry cough for 10 days. Clinical examination was normal. The chest x-ray was normal; peripheral blood film showed atypical lymphocytes (4\%); CMV PCR: $2.45 \mathrm{log}$; mild transaminitis.

4. A 37-year-old male was admitted with a history of fever for two weeks. General physical and systemic examinations were unremarkable. The laboratory tests revealed CMV PCR: 3 log; mild transaminitis.

\section{Patients take out presenting with systemic CMV infection along with gastrointestinal manifestations}

1. A 45-year-old female with past medical history of hypertension and haemorrhoids was admitted with per-rectal bleeding for 4 days and diabetic ketoacidosis. She was found to have multiple circumferential peri-anal fistulae and edematous rectal mucosa. Blood cultures grew Klebsiella pneumoniae. She further had significant perrectal bleed, for which she had CT angiogram followed by sigmoid colectomy and ileostomy.

The rectal biopsy showed inflamed granulation tissue with CMV inclusions; CMV Antigen in peripheral blood: Positive and CMV PCR: $3.34 \mathrm{log}$. She was treated with intravenous ganciclovir $(5 \mathrm{mg} / \mathrm{kg}$ twice a day for 14 days), followed by oral valganciclovir ( $900 \mathrm{mg}$ once a day) for 3 months. She subsequently had reversal of ileostomy and has remained well.

2. A 73-year-old female with past medical history of hypertension, gout and fractured neck of femur was admitted with per-rectal bleed. Colonoscopy revealed superficial ulcers in rectum. Histology of rectal biopsy showed ulceration with granulation tissue; immunohistochemistry stain was positive for CMV. CMV PCR in peripheral blood: negative; CMV IgM: negative; IgG: positive. She was later diagnosed with probable renal cell carcinoma. The diagnosis could not be confirmed as she declined biopsy. She received valganciclovir ( $900 \mathrm{mg}$ twice daily for 2 weeks), followed by once daily to complete 3 months of treatment.

3. A 77-year-old female with a previous history of ischemic heart disease and laparotomy for perforated duodenal ulcer, was admitted for lower limb cellulitis and Streptococcus dysgalactiae bacteraemia. During the course of treatment she was found to have significant drop in haemoglobin (12 gm-7 gm) with no apparent hematemesis or melena. She underwent upper gastrointestinal tract endoscopy which revealed 2 gastric ulcers. The ulcer biopsy was positive for CMV erosive gastritis. Other investigations done were - CMV PCR in peripheral blood: 3.28 logs; IgG: positive; IgM: negative. She was treated with valganciclovir ( $900 \mathrm{mg}$ twice a day), but eventually died due to complications of sepsis associated with hospital-acquired Pneumonia. 
Citation: Rao S, Pande SD, Hussain R, Ang D, Seah J (2018) Clinical Presentations of Cytomegalovirus Infection in Immunocompetent Hosts. J

Page 3 of 6

\section{Systemic CMV infection presenting with ocular- manifestations}

1. A 79-year-old male was reviewed at our eye clinic for refractory acute anterior uveitis and glaucoma. Diagnostic tests revealed PCR of aqueous humor: CMV positive, $4.91 \mathrm{log}$; CMV Ag in peripheral blood was negative. He was lost to follow-up.

2. A 53-year-old male was admitted with intractable right eye uveitis with no significant past medical history. PCR of aqueous humour:
CMV positive, 3.54 log; CMV PCR in peripheral blood: negative; CMV IgG: Positive; CMV IgM: Negative. He was treated with valganciclovir with poor compliance. He required glaucoma drainage implant 6 months after diagnosis. He received valganciclovir $900 \mathrm{mg}$ twice daily for 2 weeks followed by once daily to complete two years, as the intraocular pressure was not controlled. Subsequent PCR of aqueous humor was negative for CMV (Table1).

\begin{tabular}{|c|c|c|c|c|c|c|c|c|c|c|c|c|c|c|}
\hline $\begin{array}{l}\text { SL } \\
\text { No }\end{array}$ & $\begin{array}{l}\text { A } \\
\text { g } \\
\text { e }\end{array}$ & $\begin{array}{l}\mathbf{S} \\
\mathrm{e} \\
\mathrm{x}\end{array}$ & $\begin{array}{l}\text { Symptom } \\
\text { s }\end{array}$ & $\begin{array}{l}\text { Diagn } \\
\text { osis }\end{array}$ & CMV PCR & $\begin{array}{l}\text { CMV IgM } \\
\text { (Neg: } \\
\text { negative, } \\
\text { Pos: } \\
\text { positive, } \\
\text { ND: not } \\
\text { done) }\end{array}$ & $\begin{array}{l}\text { CMV } \\
\text { lg(Neg: } \\
\text { negative, } \\
\text { Pos: } \\
\text { positive, } \\
\text { ND: not } \\
\text { done)G }\end{array}$ & $\begin{array}{l}\text { AST } \\
\text { (normal } \\
\text { range } \quad 10 \\
\text { to } \quad 40 \\
\text { units/lit) }\end{array}$ & $\begin{array}{l}\text { ALT } \\
\text { (normal } \\
\text { range } 7 \\
\text { to } \quad 56 \\
\text { units/lit) }\end{array}$ & $\begin{array}{l}\text { ALP } \\
\text { (norma } \\
I \\
\text { range4 } \\
4 \quad \text { to } \\
147 \text { IUI } \\
\text { lit) }\end{array}$ & 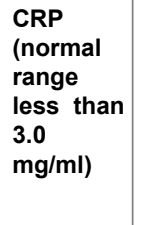 & $\begin{array}{l}\text { Procalciton } \\
\text { in (normal } \\
\text { range less } \\
\text { than } 0.15 \\
\mathrm{ng} / \mathrm{ml} \text { ) }\end{array}$ & $\begin{array}{l}\text { HIV } \\
\text { screen(ND } \\
: \quad \text { not } \\
\text { done, NR: } \\
\text { non- } \\
\text { reactive) }\end{array}$ & $\begin{array}{l}\text { IHC: } \\
\text { immun } \\
\text { ohisto } \\
\text { chemis } \\
\text { try }\end{array}$ \\
\hline 1 & 45 & $\mathrm{~F}$ & $\begin{array}{l}\text { Per rectal } \\
\text { bleeding }\end{array}$ & $\begin{array}{l}\text { CMV } \\
\text { colitis, } \\
\text { perian } \\
\text { al } \\
\text { fistula }\end{array}$ & $\begin{array}{l}2,190 \mathrm{C} / \mathrm{ml} \\
3.34 \mathrm{log}\end{array}$ & $\begin{array}{l}\text { Nonspecific } \\
\text { immunofluor } \\
\text { escence }\end{array}$ & Pos & 55 & 24 & 74 & 6.9 & ND & NR & $\begin{array}{l}\mathrm{IHC} \\
\text { stain } \\
\text { positive }\end{array}$ \\
\hline 2 & 73 & $\mathrm{~F}$ & $\begin{array}{l}\text { Per rectal } \\
\text { bleeding } \\
\text { secondary } \\
\text { to rectal } \\
\text { ulcer }\end{array}$ & $\begin{array}{l}\text { CMV } \\
\text { colitis }\end{array}$ & Not detected & $\mathrm{Neg}$ & Pos & 13 & 12 & 58 & 16.7 & 0.16 & ND & $\begin{array}{l}\text { IHC } \\
\text { stain } \\
\text { positive }\end{array}$ \\
\hline 3 & $\begin{array}{l}77 \\
Y\end{array}$ & $\mathrm{M}$ & $\begin{array}{l}\text { Haemoglo } \\
\text { bin drop } \\
\text { from } 10 \text { to } \\
7 \mathrm{gm} / \mathrm{dl}\end{array}$ & $\begin{array}{l}\text { CMV } \\
\text { gastriti } \\
\mathrm{s}\end{array}$ & $\begin{array}{l}2,81 \mathrm{c} / \mathrm{ml} 3.32 \\
\log \end{array}$ & $\mathrm{Neg}$ & Pos & 51 & 63 & 229 & 109.4 & 0.66 & NR & $\begin{array}{l}\text { IHC } \\
\text { stain } \\
\text { positive }\end{array}$ \\
\hline 4 & $\begin{array}{l}37 \\
Y\end{array}$ & $\mathrm{M}$ & $\begin{array}{l}\text { Fever for } \\
3 \text { weeks }\end{array}$ & PUO & $\begin{array}{l}569 \mathrm{C} / \mathrm{ml} 2.76 \\
\log \end{array}$ & ND & ND & 62 & 92 & 165 & 27.4 & 0.39 & NR & ND \\
\hline 5 & $\begin{array}{l}32 \\
Y\end{array}$ & M & $\begin{array}{l}\text { Fever for } \\
3 \text { weeks }\end{array}$ & PUO & $\begin{array}{l}199 \mathrm{C} / \mathrm{ml} \\
2.30 \mathrm{log}\end{array}$ & Pos & Pos & 212 & 258 & 163 & 9.4 & 0.2 & NR & ND \\
\hline 6 & $\begin{array}{l}37 \\
Y\end{array}$ & $M$ & $\begin{array}{l}\text { Fever for } \\
3 \text { weeks }\end{array}$ & PUO & $\begin{array}{l}993 \mathrm{C} / \mathrm{ml} \quad 3.00 \\
\log \end{array}$ & ND & ND & 43 & 77 & 112 & 14.7 & 0.48 & NR & ND \\
\hline 7 & $\begin{array}{l}31 \\
Y\end{array}$ & $M$ & $\begin{array}{l}\text { Fever for } \\
3 \text { weeks }\end{array}$ & PUO & $\begin{array}{l}282 \mathrm{C} / \mathrm{ml} \\
2.45 \mathrm{log}\end{array}$ & ND & ND & 70 & 129 & 83 & 5.8 & ND & NR & ND \\
\hline 8 & $\begin{array}{l}79 \\
Y\end{array}$ & M & $\begin{array}{l}\text { Red } \\
\text { eye(right) }\end{array}$ & Uveitis & $\begin{array}{l}\text { CMV DNA } \\
\text { detected in } \\
\text { aqueous } \\
\text { humor(serum: } \\
\text { not done) }\end{array}$ & ND & ND & 9 & ND & ND & ND & ND & ND & ND \\
\hline 9 & $\begin{array}{l}53 \\
Y\end{array}$ & $\mathrm{M}$ & $\begin{array}{l}\text { Red } \\
\text { eye(right) }\end{array}$ & Uveitis & $\begin{array}{l}\text { CMV DNA } \\
\text { detected in } \\
\text { Aqueous } \\
\text { humor } \\
\text { (undetected in } \\
\text { serum) }\end{array}$ & $\mathrm{Neg}$ & Pos & 29 & 30 & 62 & 0.8 & ND & NR & ND \\
\hline
\end{tabular}

Table 1: Summary of all the patients with details of sex, disease, detection and results.

\section{Discussion}

Seroprevalence of CMV has been reported between 45 to $100 \%$, highest being in South America, Africa and Asia and lowest in Western Europe and USA [2].
Reactivation of CMV leads to systemic manifestations which are commonly seen in immunocompromised individuals especially in solid organ transplant and Human Immunodeficiency Virus (HIV) patients [1].

CMV infection may affect various systems and can present as meningoencephalitis, retinitis, hepatitis, colitis or enteritis, 
pneumonitis, pancreatitis, nephritis, early myocarditis, graft rejections. Primary infection in pregnant women can lead to congenital CMV syndrome in new-borns.

CMV infection with clinical manifestations has, however, been rarely reported in immunocompetent subjects. In our study, we reviewed CMV positive cases in otherwise healthy subjects. They were admitted for various medical conditions and subsequently confirmed to have CMV infection.

Infections with $\mathrm{CMV}$ can be varied from a prolonged fever to serious, life-threatening manifestations. In severe manifestations, there seems to be a role for antiviral treatment along with surgery, where deemed necessary.

Gastrointestinal (GI) involvement has been the commonest site for CMV infection, leading to gastroenteritis, duodenitis, colitis, proctitis and exacerbation of pre-existing inflammatory bowel disease [1-4]. CMV prevalence rate in GI biopsies of 9/1000 has been reported. In GI infection, CMV can also present as generalised symptoms with or without bloody diarrhoea and melena [1,5]. Another recent study found that primary CMV infection in IBD patients on immunomodulators can cause severe clinical manifestations and hence should be thought of even in low seroprevalence areas [6].

Patients with IBD are more prone for complications as a result of CMV colitis, i.e., megacolon, fistula, perforation and peritonitis [1].

Three female patients from our study had CMV infection presenting with gastrointestinal manifestations. We observed that GI presentation of CMV was per-rectal bleeding in 2 patients, of whom one had perianal fistula needing colectomy with ileostomy. Second patient had rectal ulceration with granulation tissue. Both recovered well during follow-up. Due to the severity of their symptoms and clinical features they needed supportive care and long in-patient stay.

The third patient was confirmed CMV positive on biopsy of 2 gastric ulcers, when presented to hospital with low haemoglobin ( 7 $\mathrm{gm} / \mathrm{dl}$ ). She died as a result of hospital-acquired pneumonia. All of them received antiviral-treatment.

In CMV patients with GI symptoms, the mortality rate has been reported to be in between $6.2 \%$ to $32 \%$ [1]. The higher mortality has been associated with patients above the age of 55 years and with those who have compromised immunity.

CMV colitis in immunocompetent people has been reported, but is rare; a vast majority of patients were found to have associated comorbidities including diabetes mellitus, renal failure, and Inflammatory Bowel Disease (IBD) and HIV infections. Two patients from our colitis presentation did not have any significant comorbidity. The third one declined further tests for renal cell carcinoma. We observed patients with GI presentation of CMV were older with prolonged hospitalisations and higher morbidity.

The probable reason for presence of CMV in the colon with IBD may be related to bowel wall inflammation leading to cytokine release further resulting in activation of CMV replication [3,7]. Treatment with steroids is associated with positive blood PCR, but not with clinical disease. The CMV DNA levels seem to relate with adjustment of steroid dose.

The benefits of treatment of CMV colitis are not clear as CMV is known to resolve spontaneously in immunocompetent hosts. However, we noted that especially, immunocompetent elderly with colitis, had severe clinical presentations. These were from per-rectal bleed, needing blood transfusions to peri-anal fistulae needing colostomy and prolonged in-patient stay. Due to presence of fistulae they were thoroughly investigated but found to be negative for IBD.

Although there are no guidelines on management of CMV in immunocompetent hosts, we however found guidelines in relation to immunocompromised individuals and those with IBD.

The American College of Gastroenterology and European Crohn's and Colitis Organisation (ECCO) state that routine screening for CMV is not necessary prior to the starting of immunosuppressive therapy in IBD. However, in steroid resistant colitis, CMV should be excluded before increasing immunotherapy. In severe steroid resistant colitis with CMV detected in the mucosa during immunomodulation therapy, antiviral therapy should be started and immunomodulators discontinued, until colitis symptoms improve [8]. "The British Society of Gastroenterology' (BSG) guidelines suggest treatment of CMV and discontinuation of immunosuppression in refractory colitis when CMV is detected by histology and PCR [9].

Central nervous system (CNS) involvement is also well-documented in immunocompetent people from previous studies. They can present with generalised symptoms along with motor or sensory deficits, encephalitis, visual field defects, and continence issues [1]. GuillainBarre' syndrome, transverse myelitis, diffuse axonal neuropathy and cranial nerve palsies also have been reported [10-13].

From our small retrospective sample we did not have any confirmed diagnosis of CNS CMV. Haematological abnormalities are known in immunocompetent people with CMV infection which includes thrombocytopenia, pancytopenia, disseminated intravascular coagulation and myelodysplastic changes [1]. Apart from the atypical lymphocytes seen on peripheral blood film we did not observe any other haematological abnormalities in our series. In those with sepsis and hospital-acquired infections as in 3 of our patients, it was difficult to conclude if the haematological and liver dysfunctions were due to CMV itself or a result of severe sepsis. CMV infection may be a procoagulant state, leading to thrombosis at various sites often in the absence of known risk factors for hypercoagulability $[1,14,15]$. These complications were not seen in our patients.

Eye involvement in CMV presents as uveitis, retinitis and corneal involvement and papillitis [16,17]. Anterior uveitis may be more common in immunocompetent patients due to a stronger immune response, nevertheless with long term complications [18-22].

We observed 2 patients (aged 79 and 53 years) with no systemic evidence of immunosuppression who were referred to us by our eye clinic. Both presented with anterior uveitis and had glaucoma, and for both, the diagnoses were confirmed by PCR of aqueous humor. One received valgancilcovir and during the follow-up period one of them required glaucoma drainage implant.

Although we did not observe lung involvement from our study, CMV can cause pneumonia or interstitial pneumonitis with lymphadenopathy and generalised symptoms [1]. Pulmonary CMV has been reported in high frequency in a recent study of critically unwell immunocompetent patients.

It appears from the current literature that CMV in immunocompetent people is not as rare as previously thought. The increased recognition of the syndromes as caused by CMV may be due to improved diagnostic techniques like PCR and immunohistochemistry [1]. 
Also, the severity and complications of clinical manifestations due to CMV infection can range from mild and self-limiting to severe and life-threatening to chronic. The role of treatment is not clearly established in immunocompetent people. In majority of the cases, the infection is likely self-limiting. However, antiviral treatment should be initiated weighing benefits vs. adverse effects from treatment in severe cases [1]. The adverse effects of treatment with ganciclovir/ valganciclovir may include, but not limited to: Cytopenias; Seizures; Nephrotoxicity; Fertility impairment; Stevens-Johnson syndrome, etc. There seems to be a role for anti-viral treatment along with appropriately chosen surgery in selected, severe cases.

\section{Limitations of Study}

Small numbers and retrospective nature of study. Due to single center study, our patient group may not be fully representative.

\section{Conclusion}

From our study we conclude that CMV infection can present in healthy and immunocompetent subjects with various clinical manifestations. Our case series suggest that younger patients presenting with PUO have relatively mild illness. CMV infection of eye can result in long term morbidity. Elderly people are prone for more severe gastrointestinal manifestations, and need interventions and prolonged hospitalisation. Early detection and intervention may help to reduce morbidity and mortality in these patients.

Currently no clear guidelines are available on treatment of CMV in immunocompetent hosts. Treatment is based on severity, age, comorbidities and site of infection.

We conclude that based on our experience and all available literature, CMV screening for immunocompetent patients can be considered:

1. For patients with PUO in the absence of other infections or diagnoses contributing to fever.

2. System-based screening of patients as indicated by clinical signs and symptoms as elaborated above.

3. It is clinically difficult to distinguish between acute vs. chronic and reactivation of CMV infection. CMV IgM antibody and/or paired IgG antibody with rising titres can be considered for these scenarios. However, this distinction does not help in making therapeutic decisions.

4. CMV quantitative PCR and histopathology of appropriate specimens can assist in diagnosis in suitable cases.

5. A conservative approach with close monitoring may be adopted for milder cases. For patients with severe manifestations, treatment should be considered based on its benefits vs. side effects.

\section{References}

1. Rafailidis PI, Mourtzoukou EG, Varbobitis IC, Falagas ME (2008) Severe cytomegalovirus infection in apparently immunocompetent patients: a systematic review. Virol J 5: 47.

2. Cannon MJ, Schmid DS, Hyde TB (2010) Review of cytomegalovirus seroprevalence and demographic characteristics associated with infection. Rev Med Virol 20: 202-213.

3. Galiatsatos P, Shrier I, Lamoureux E, Szilagyi A (2005) Meta-analysis of outcome of cytomegalovirus colitis in immunocompetent hosts. Dig Dis Sci 50: 609-616.
4. Karakozis S, Gongora E, Caceres M, Brusn E, Cook JW (2001) Lifethreatening cytomegalovirus colitis in the immunocompetent patients: report of the a case and review of the literature. Dis Colon Rectum 44: 1716-1720.

5. Patra S, Samal SC, Chacko A, Mathan VI, Matham MM (1999) Cytomegalovirus infection of the human gastrointestinal tract. J Gastroenetro Hepatol 14: 973-976.

6. Rowan C, Judge C, Cannon MD, Cullen G, Mulcahy HE, et al. (2018) Severe symptomatic primary CMV infection in inflammatory bowel disease patients with low population seroprevalence. Gastroenterol Res Prac 2018: 1-5.

7. Goodman AL, Murray CD, Watkins J, Griffiths PD, Webster DP (2015) $\mathrm{CMV}$ in the gut: a critical review of CMV detection in the immunocompetent host with colitis. Eur J Clin Microbiol Infect Dise 34: 13-18.

8. Kornbluth A, Sachar DB (2010) Practice Parameters Committee of the American College of Gastroenetrology Ulcerative colitis practice guidelines in adults: American college of Gastroeneterology, Practice parameters committee. Am J Gastroenerol 105: 501-523.

9. Carter MJ (2011) Guidelines for the management of inflammatory bowel disease in adults. Gut 60: 571-607.

10. Orlikowski D, Porcher R, Sivadon-Tardy V, Quincampoix JC, Raphael JC et al. (2011) Guillain-Barre syndrome following primary cytomegalovirus infection: a prospective cohort study. Clin Infect Dis. 52: 837-844.

11. Tyler KL, Gross RA, Cascino GD (1986) Unusual viral causes of transverse myelitis: hepatitis A virus and cytomegalovirus. Neurology 36 : 855-858.

12. Giobbia M, Carniato A, Scotton PG, Marchiori GC, Vaglia A (1999) Cytomegalovirus-associated transvers myelitis in a nonimmunocompromised patient. Infection 27: 228-230.

13. Horwitz CA, Henle W, Henle G, Snover D, Rudnick H et al. (1986) Clinical and laboratory evaluation of cytomegalovirus-induced mononucleosis in previously healthy individuals. Medicine 65: 124-134.

14. Squizzato A, Ageno W, Cattaneo A, Brumanna N (2007) A case report and literature review of portal vein thrombosis associated with cytomegalovirus infection in immunocompetent patients. Clin Infec Dis 44: e13-e16.

15. Abgueguen P, Delbos V, Chennebault JM, payan C, Pichard E. Vascular thrombosis and acute cytomegalovirus infection in immunocompetent patients: report of 2 cases and literature review. ' Clin Infec Dis 36: e134e139.

16. Markomichelakis NN, Canakis C, Xafirakis P, Marakis T, Mallias L et al. (2002) Cytomegalovirus as a cause of anterior uveitis with sectoral iris atrophy. Opthalomogy 109: 879-882.

17. deSchryver I, Rozenberg F, Cassoux N, Michelson S, KestelyN P, et al. (2006) Diagnosis and treatment of cytomegalovirus iridocyclitis without retinal necrosis. Br J Opthalmol 90: 852-855.

18. Chee SP, Bacsal K, Jap A, Se-Thoe SU, Cheng CL et al. (2008) Clinical features of cytomegalovirus anterior uveitis in immunocompetent patients. Am J Opthalmol 145: 834-840.

19. Van Boxtel LA, van der Lelij A, van der Meer J, Los LI (2007) Cytomegalovirus as a cause of anterior uveitis in immunocompetent patients. Opthalmology 114: 1358-1362.

20. Miyanaga M, Sugita S, Shimizu N, Morio T, Miyata K, et al. (2010) A significant association of viral loads with corneal endothelial cell damage in cytomegalovirus anterior uveitis. Br J Opthalomol 94: 336-340.

21. Babu K, Murthy GJ (2013) Cytomegalovirus anterior uveitis in immunocompetent individuals following topical prostaglandin analogues. J Opthalmic Inflamm Infect 3: 55.

22. Zambrano H, Rivera L, Vega R, Ordoriez C, Vera-Bermudez J, et al. (2018) Detection of Cytomegalovirus in pulmonary samples of critically ill, immunocompetent patients using a real time PCR based method: Preliminary findings of a prospective study. Int J Infec Dis 73: 44. 